\title{
LA INESTABILIDAD DEL SISTEMA ELECTORAL Y EL FRACASO DE LA «DEMOCRAZIA GOBERNANTE» EN ITALIA (2008-2018)
}

\section{The instability of the electoral system and the failure of the "democrazia gobernante" in Italy (2008-2018)}

\author{
MANUEL ÁLVAREZ TARDÍO \\ Universidad Rey Juan Carlos \\ manuel.tardio@uric.es
}

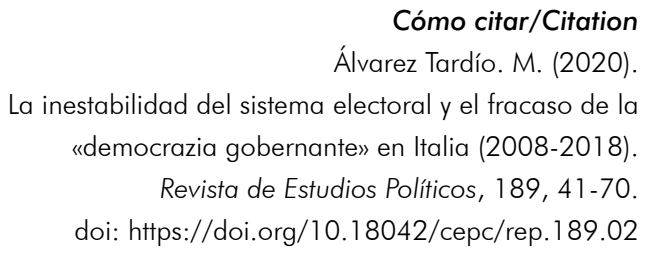

Resumen

Este artículo se ocupa de la evolución del sistema electoral de la segunda república de Italia durante el período de 2008 a 2018. Se parte de la reforma llevada a cabo en 2005 por la coalición de centroderecha y se concluye con la modificación legislativa acordada antes de las elecciones generales de marzo de 2018. En un primer nivel se describen y estudian los contextos y las causas que han contribuido a la alta variabilidad en materia de sistemas electorales; se incluye el nivel interpartidista, pero también un factor exógeno como la interferencia judicial. En un segundo nivel se debate sobre las líneas y direcciones de la compleja relación entre el sistema electoral, el sistema de partidos y el régimen parlamentario, partiendo de una reflexión sobre las aportaciones teóricas en ese campo. Se concluye analizando, dentro de ese segundo nivel, el especial significado de la reforma de 2015, así como su fracaso en términos de bloqueo de la democrazia gobernante.

\section{Palabras clave}

Sistema electoral; partidos políticos; democracia; Italia; elecciones. 


\begin{abstract}
This article deals with the evolution of the electoral system of the Italian Second Republic during the period from 2008 to 2018. It starts with the reform carried out in 2005 by the center-right coalition and concludes with the legislative modification agreed before the general elections of March 2018. On a first level, the contexts and causes that have contributed to the high variability in electoral systems are described and studied; the interpartisan level is included but also an exogenous factor such as judicial interference. On a second level, the lines and directions of the complex relationship between the electoral system, the party system and the parliamentary regime are discussed, based on a reflection on the theoretical contributions in that field. It concludes by analyzing, within that second level, the special meaning of the 2015 reform, as well as its failure in terms of blocking the «democrazia gobernante».
\end{abstract}

\title{
Keywords
}

Electoral system; political parties; democracy; Italy; elections. 
I. INTRODUCCIÓN. II. LA INESTABILIDAD DE UNA DÉCADA. III. LA ACCIDENTADA VIDA DE LA LEY CALDEROLI. IV. EL FRACASO DE LA REFORMA MÁS AMBICIOSA. V. UN NUEVO Y CRITICADO RÉGIMEN MIXTO. VI. REFORMA ELECTORAL Y GOBERNABILIDAD. EL FRACASO DEL ITALICUM. VII. CONSIDERACIÓN FINAL. BIBLIOGRAFÍA.

\section{INTRODUCCIÓN}

Pocos días antes de la Navidad de 2012 el presidente de la República italiana se dirigía a los líderes políticos del país en estos duros términos: «Es imperdonablemente grave que no se hayan puesto de acuerdo para reformar la ley electoral» ${ }^{1}$. La Corte Costituzionale (en adelante Tribunal Constitucional), recordó Giorgio Napolitano, había "planteado serias dudas de legitimidad» sobre el sistema electoral vigente. Sin embargo, haciendo caso omiso a las «fuertes y tenaces» voces «de la sociedad civil y del mundo del derecho», los partidos mayoritarios no habían cambiado la ley electoral y ahora Italia se enfrentaba a unas elecciones con una norma de dudosa «legitimidad». Entre tanto, días antes el Popolo della Libertà, la coalición liderada por Silvio Berlusconi, había retirado su apoyo al Ejecutivo presidido por Mario Monti. Era la enésima crisis en un país en el que la inestabilidad gubernativa parecía la norma.

Siete años después de aquellas palabras la cuestión continuaba abierta. El 10 de septiembre de 2019 se conocía el resultado sorprendente de la crisis planteada por la ruptura entre los dos socios de Gobierno, el Movimento Cinque Stelle (M5S) de Luigi Di Maio y la Lega de Matteo Salvini. El primero acababa de llegar a un acuerdo con el Partito Democratico (PD), al que durante años había estado radicalmente enfrentado. El nuevo Gobierno, presidido otra vez por Giuseppe Conte, se presentaba ante la opinión con un programa que incluía, amén de otras «reformas estructurales», la aprobación de una nueva ley electoral. No era esta una de las prioridades del socio mayoritario, el partido fundado años

\footnotetext{
$1 \quad$ El Pais, 17-12-2012.
} 
atrás por Beppe Grillo, sino que, según diversas fuentes, el empeño principal en esa reforma electoral partía nuevamente del $\mathrm{PD}^{2}$.

Ciertamente, la política italiana lleva más de veinticinco años sumida en un proceso experimental en materia de legislación electoral. Contra lo que se ha sostenido a veces por la literatura científica, parece empeñada en mostrarnos que las reformas electorales no tienen por que ser excepcionales en una democracia consolidada (Katz, 2005; Renwick, 2010; Nohlen, 2004; Norris, 1997). La llamada segunda república echó a andar con una nueva ley electoral que estuvo vigente hasta 2005, momento en el que se aprobó un cambio sustantivo - esta era la ley a la que se refería el discurso de Napolitano-. Pero el nuevo sistema no alcanzaría la década de vida, al ser parcialmente anulado por el Tribunal Constitucional en 2014. Desde entonces hasta finales de 2019 las elecciones generales se han celebrado con dos sistemas diferentes y, por si esto fuera poco, una importante y ambiciosa reforma electoral aprobada por las Cámaras en 2016 quedó inservible tras la celebración de un referéndum nacional y un nuevo pronunciamiento del Alto Tribunal.

El objetivo de este artículo es doble. Primero, clarificar y analizar la enrevesada evolución de la política de reformas electorales en la Italia de la década previa a 2018, partiendo de la ley de 2005. Para esto será necesario referirse no solo a la actividad del legislativo, sino también a las consecuencias de la novedosa interferencia judicial iniciada en 2014. Con la finalidad de establecer un objeto de estudio preciso y a sabiendas de la provisionalidad de la legislación italiana en el campo electoral, se ha acotado el período de análisis hasta la fecha tope de las elecciones generales celebradas el 4 de marzo de 2018. Y, en segundo lugar, hacer un balance de la evolución italiana en materia de regímenes electorales a la luz de los principales debates planteados por los especialistas, especialmente en lo referido tanto a las motivaciones de los cambios como a la relación entre el sistema de partidos, el sistema electoral y la gobernabilidad. Por otra parte, este artículo se ha diseñado a sabiendas de que forma parte de un dossier monográfico sobre la evolución de la vida política italiana entre los años 2008 y 2018; por consiguiente, lo que aquí se analiza debe ser complementado y matizado por otros factores abordados en el resto del dossier.

\section{LA INESTABILIDAD DE UNA DÉCADA}

La interminable historia de las reformas electorales en la Italia reciente empezó en agosto de 1993, cuando se aprobaron dos nuevas leyes. No fueron

2 El Mundo, 10-9-2019 y 8-10-2019. 
consecuencia de una iniciativa interna, sino resultado de la presión externa. La grave crisis política con motivo de las investigaciones judiciales de «Manos limpias" y algunas iniciativas sociales presionaron a favor de la modificación del sistema proporcional de grandes circunscripciones vigente desde 1946 y levemente corregido en 1948 para paliar la fragmentación. Si bien se habían sucedido intentos de reforma mediante la constitución de comisiones bicamerales, como la que había funcionado entre 1983 y 1985, el resultado había sido nulo. Atrás quedaban varias décadas en las que, salvo algún cambio rápidamente revertido ${ }^{3}$, las elecciones italianas se habían celebrado con un escrutinio proporcional concebido - aunque no constitucionalizado- en tiempos de consenso antifascista para contribuir a la primacía del legislativo sobre el ejecutivo ${ }^{4}$ (Pappalardo, 1995: 62-66; Pasquino, 1994: 30; Groppi, 2008: 157-159, 162; Donovan, 1996; Renwick et al., 2009: 438; Katz, 2005: 65).

La nueva normativa modificó la forma de elección de ambas Cámaras que en el caso de Italia son cotitulares de la capacidad legislativa y de la investidura del Gobierno-, introduciendo «una mezcla entre lo proporcional y lo mayoritario» (Pasquino, 1994: 32), si bien con «un componente mayoritario predominante» (Chiaramonte, 2015: 12). Era la respuesta a un clima de opinión contrario al reparto proporcional, así como a la expectativa de que la fragmentación de las Cámaras, la inestabilidad de los Gobiernos e incluso la corrupción se podrían atajar introduciendo una corrección mayoritaria. El fruto de un "tiempo turbulento» (Baldini, 2011: 650) en el que se esperaba mucho de un cambio en el sistema electoral y no se advertían el terremoto que estaba por venir en el sistema de partidos (Crainz, 2015: 179).

El nuevo régimen mixto con que se inauguró la segunda república dividía el reparto de escaños en dos bloques. El $75 \%$ se elegía en circunscripciones uninominales donde el más votado se llevaba el puesto - esto era igual para los dos Cámaras-. Y el otro $25 \%$ variaba en función de la Cámara: en el caso de los Diputados había un reparto proporcional a nivel nacional entre listas bloqueadas, en función de los votos no utilizados en el circuito mayoritario y previa eliminación (scorporo) de los ya obtenidos por los candidatos elegidos en el uninominal; y en el caso del Senado se beneficiaba a los candidatos más votados pero que no habían conseguido ser electos, dentro de un reparto proporcional a nivel regional. Por último, había una barrera de acceso al

3 La conocida como legge truffa o ley fraude. Aprobada en 1953, llegó a estar vigente en las elecciones de julio de ese año, pero poco después fue derogada y se continuó con el sistema de 1948 (Groppi, 2008: 159).

4 Aunque, en el caso del Senado, si se lograba el inalcanzable porcentaje del $65 \%$ en la circunscripción uninominal, regía el principio mayoritario FPTP. 
reparto proporcional situada en el $4 \%$ de los votos válidos a escala nacional (Chiaramonte, 2015: 12-13; Groppi, 2008: 162-163).

Este sistema electoral, conocido como el Mattarellum, estuvo vigente hasta 2005 y durante tres convocatorias electorales. Como hubo una radical transformación en el sistema de partidos durante los noventa, la nueva regulación propició el protagonismo de dos grandes coaliciones. Se logró una cierta racionalización al desarrollarse una competencia bipolar — «bipolarismo fragmentado» a decir de D'Alimonte (2005) — que favorecía, a priori, la gobernabilidad. Además, la formación de coaliciones de Gobierno pasó a ser preelectoral. Sin embargo, a medio plazo pronto se vio que, en plena reformulación de la división clásica izquierda-derecha, el incentivo a la formación de coaliciones perjudicó a la institucionalización de los nuevos partidos. La paradoja estuvo, así, en que el nuevo bipolarismo no eliminó la fragmentación de las Cámaras e incluso, en determinados momentos, pareció incentivarla. Pues los grupos minoritarios, erigidos en actores indispensables para construir esas coaliciones, esgrimían con éxito sus porcentajes de voto para condicionar la formación y estabilidad de los Gobiernos. De este modo, tras diez años con la nueva ley electoral, la media de duración de los Gobiernos solo mejoró ligeramente, con siete Gobiernos en ese período (D'Alimonte, 2005: 273; Chiaramonte, 2015: 13-15; Massetti, 2006: 263).

\section{LA ACCIDENTADA VIDA DE LA LEY CALDEROLI}

En 2005 el sistema electoral Mattarellum dejó paso a otro régimen bajo el que se celebraron tres convocatorias electorales, dos de las cuales, las de 2008 y 2013, entran dentro del período que nos ocupa. El centroderecha fue quien promovió y aprobó esa nueva ley electoral. Habitualmente se seńala que fue el resultado de las malas perspectivas con que la coalición liderada por Silvio Berlusconi iba a afrontar las próximas elecciones generales, sobre todo después de unos pobres resultados en las consultas regionales y, lo que es más importante, ante la reagrupación del centroizquierda bajo el liderazgo del expresidente de la Comisión Europea Romano Prodi (Groppi, 2008: 167). Sin embargo, otros autores han mostrado que la reforma de 2005 respondió a una confluencia de factores más compleja, de tal modo que la maximización de los resultados en un contexto de caída de las expectativas de voto fue solo uno entre varios; habrían contado también, y mucho, la cuestión del reparto de poder dentro de la coalición gobernante y la gestión de expectativas de cada uno de sus integrantes con uno u otro sistema electoral (Renwick et al., 2009: 441-445; Chiaramonte, 2015: 15). Por otra parte, tampoco hay que olvidar que el Mattarellum había sido objeto de críticas bien argumentadas desde el 
campo académico, destacando la formulada por el politólogo Giovanni Sartori, que, al igual que su colega Gianfranco Pasquino, había postulado para Italia una fórmula mayoritaria a dos vueltas al estilo de la vigente en la V República francesa (Pasquino, 2007: 86).

En todo caso, el carácter oportunista de aquella reforma parece incuestionable; eso, unido a la oleada de críticas desde el centroizquierda, «escandalizado por el cambio en las reglas del juego" justo antes de unas elecciones (Massetti, 2006: 264), se tradujo en que la nueva ley aprobada en diciembre de 2005 nació con una expectativa de consolidación muy baja. Fue conocida como Porcellum, una etiqueta despectiva asignada por Sartori para realzar de forma irónica la porcata (cerdada) que la impulsaba y que había reconocido explícitamente uno de sus principales diseñadores, el parlamentario Roberto Calderoli (Fernández Esquer, 2019: 212).

El nuevo sistema electoral daba por concluida la larga década de sistema mixto e instauraba la vuelta al proporcional. El centroderecha quería suprimir las circunscripciones uninominales por entender, en parte, que habían penalizado sus resultados en 1996 y 2001, pero, sobre todo, porque esperaba que no le fueran favorables ante la reagrupación del voto de centroizquierda (Chiaramonte, 2015: 15). Así, la nueva norma estableció circunscripciones plurinominales (veintiséis para la Cámara de Diputados y de diseño regional en el caso del Senado; además de una circunscripción exterior única para los italianos residentes en el extranjero) y voto de listas bloqueadas (Groppi, 2008: 168). Este segundo aspecto, la eliminación del voto preferencial, como se verá objeto de impugnación en los tribunales, fue una de las prioridades del grupo de Berlusconi y de la Unione dei Democratici Cristiani e Democratici di Centro (UDC), su aliado en el centroderecha, en tanto que estos lo concebían como un incentivo para la centralización intrapartidista y una mayor disciplina durante la fase de designación de candidatos (Renwick et al., 2009: 444; Pasquino, 2007: 81). En esa misma línea, con el objetivo de reforzar el peso de las direcciones nacionales en la selección de los futuros parlamentarios y a la vez explotar el impacto mediático de los principales líderes nacionales, la nueva ley permitía que los candidatos figuraran en varias listas a la vez y decidieran luego, a posteriori del recuento, el escaño que mejor les conviniera de haber obtenido la victoria en más de uno5.

5 En las primeras elecciones con el nuevo sistema Berlusconi fue cabeza de lista en todas las circunscripciones. En cuanto a Prodi, también estuvo en varias. Como señaló tempranamente Pasquino (2007: 88), este sistema permitía a los cabezas de lista condicionar, con su elección a posteriori, la composición de su grupo parlamentario. 
No obstante, el regreso al sistema proporcional no fue tal realmente porque la ley establecía que, si después de un primer recuento ninguna de las listas alcanzaba el $55 \%$ de los votos, entraba en funcionamiento un premio di maggioranza (premio de mayoría): la lista nacional más votada, con independencia del porcentaje conseguido, recibía automáticamente los escańos que le faltaran para llegar a 340, una cifra equivalente al 53,9\% del total en la Cámara de los Diputados. Por tanto, no se fijaba un umbral mínimo para el premio, motivo que, como se verá, fue el principal escollo en la cuestión de constitucionalidad posterior. Por otra parte, en el Senado también operaba un premio de mayoría, si bien se aplicaba a nivel de circunscripciones, esto es: siempre que en una región ninguna lista lograra el $55 \%$ de los escaños disponibles, la más votada se llevaba el premio (Groppi, 2008: 169-170).

Paradójicamente, si una de las probables intenciones del legislador con el premio de mayoría había sido corregir la proporcionalidad y favorecer la formación de Gobierno, al establecer un sistema diferente para el Senado no tenían por qué coincidir las mayorías resultantes en las dos Cámaras, por lo que aumentaba la incertidumbre ${ }^{6}$. Sin embargo, cabe recordar que tras la decisión de introducir ese premio, el principal partido del centroderecha buscaba incentivar la formación de coaliciones preelectorales, consciente de que pasaba por un momento de debilidad y que el enfrentamiento con sus potenciales aliados, si derivaba en fragmentación de la oferta, podía ser decisivo ante un centroizquierda más unido que nunca (Chiaramonte, 2015: 15-16; Fusaro, 2016: 557). Además, aunque el premio en el Congreso pudiera beneficiar hipotéticamente a la coalición encabezada por Prodi, los mecanismos correctores - y el hecho de que el premio se obtuviera de forma diferente en cada Cámara- contribuirían a debilitar la mayoría lograda por los ganadores.

Porque también se corregía el proporcionalismo mediante un sistema de barreras - nacional para la Cámara de Diputados y regional para el Senadoque, sin duda, incentivaban la conformación de listas de coalición antes de las elecciones. Para tomar parte en el recuento de la Cámara de Diputados se fijaban dos umbrales a nivel nacional: uno del $4 \%$ si se concurría por separado y otro del $10 \%$ si se trataba de una coalición. Además, solo entraban al reparto

En el caso de Berlusconi, pero también del líder de la Liga Norte, Umberto Bossi, era asimismo un instrumento para sortear el problema de posibles elecciones primarias.

6 Hay que recordar además que la barrera de edad para acceder al voto era diferente en el Congreso y el Senado, dieciocho frente a veinticinco ańos, respectivamente. Eso, con independencia del premio de mayoría, también podía tener cierta influencia en la configuración de mayorías diferentes en las dos cámaras. 
las listas coaligadas que individualmente hubieran pasado del $2 \%{ }^{7}$ (Groppi, 2008: 169).

La ley de 2005 recibió de inmediato una oleada de «apasionadas» críticas de la oposición e incluso de "antiguos comunistas y cristianodemócratas». Romano Prodi la calificó de «anti-patriottica, inconstituzionale, antidemocratica», si bien, paradójicamente, se convertiría en breve en presidente del Consejo gracias a una mayoría lograda con el premio que fijaba Porcellum ${ }^{8}$ (Pasquino, 2007: 89). Que esta ley fue objeto de fuerte discusión desde su mismo nacimiento lo revela el hecho de que se intentara utilizar la fórmula del referéndum abrogativo para anularla o modificarla. Ocurrió hasta dos veces: en la primera se llegó a votar en junio de 2009, pero sin que se alcanzara el nivel mínimo de participación exigido por la Constitución; y en la segunda, tres ańos más tarde, y en la que se pretendía recuperar la vigencia del Mattarellum, fue el Tribunal Constitucional el que impidió la consulta (Fernández Esquer, 2019: 215).

Si no dieron frutos los intentos de canalizar desde abajo la protesta, tampoco lo dio la presión ejercida por el presidente Napolitano en 2012. Este se hizo eco no solo de una corriente de opinión en contra de la ley Calderoli, sino que, como se ha explicado más arriba, actuó como amplificador de las críticas planteadas por el Tribunal Constitucional sobre la «legitimidad» de algunos aspectos de ese régimen electoral ${ }^{9}$. Al final, fuera por el cortoplacismo inherente a la competición interpartidista que tanto irritaba a Napolitano o por la dificultad de acordar una reforma cuando el sistema de partidos empezaba a cambiar y las incertidumbres crecían, lo cierto es que la ley de 2005

7 A lo que se ańadía la lista miglior perdente (mejor perdedora), esto es, la que no habiendo llegado al 2\%, hubiera tenido el mejor resultado. Las barreras en el Senado eran algo diferentes y se computaban a nivel regional: más baja (1,8\%) si se trataba de listas individuales; más alta $(20 \%)$ si eran coaliciones (con el mínimo del $3 \%$ por integrante para acceder al reparto; y sin la opción del miglior perdente).

8 En las primeras elecciones celebradas con la nueva ley el centroizquierda se llevó el premio en el Congreso de los Diputados con el 49,8\% de los votos, solo una décima por encima de sus oponentes. En el Senado, «la suma de los premios regionales» dio la victoria por un escaso margen a la coalición liderada por Berlusconi; no obstante, el voto de las circunscripciones de Valle d'Aosta y Trentino Alto Adige, así como el de los italianos en el exterior, otorgaron finalmente la victoria a la unión de centroizquierda, que logró nueve de los doce escaños restantes (Groppi, 2008: 170-171).

9 Napolitano se refería a varios pronunciamientos del Tribunal Constitucional. Y es que este había advertido en 2008 sobre lo que consideraba «aspectos problemáticos» de la ley de 2005, especialmente el hecho de que no se subordinara «la concesión del premio de mayoría al logro de una cantidad mínima de votos» (Milani y Sorda, 2015: 26). 
seguía vigente cuando se celebraron las elecciones generales en 2013. Fue entonces, precisamente, cuando el patrón de bipolaridad entre dos grandes coaliciones a izquierda y derecha se vio sacudido por la irrupción, como en otras partes de Europa, de un nuevo grupo con una retórica populista, el M5S, la formación política más votada, con un 25,6\% de los votos (Del Palacio, 2018: 223-224; D'Alimonte, 2013).

En la nueva legislatura hubo dos intentos de impulsar una reforma electoral desde dentro, pero ninguna de las dos comisiones logró nada sustantivo, si bien la presidida por el historiador y politólogo Gaetano Quagliarello, a la sazón ministro para la Reforma Constitucional en el Gobierno de Enrico Letta, produjo un elaborado informe sobre la cuestión ${ }^{10}$. Por consiguiente, ni la vía del referéndum abrogatorio ni la parlamentaria consiguieron acabar con la ley Calderoli. Su abrupto final llegó a comienzos de 2014 cuando el Tribunal Constitucional declaró inconstitucionales dos puntos de esa norma. Aunque esta seguía vigente, como lo anulado era capital para el sentido de su aplicación, el resultado en la práctica fue que se regresó a un sistema proporcional sin corrección sustantiva y que llegó a conocerse como el Consultellum.

El Alto Tribunal declaró no conforme con la Constitución tanto la prima de mayoría como las listas bloqueadas, aun cuando el régimen electoral italiano no está constitucionalizado. El Tribunal decidió romper con su propia jurisprudencia —entre otras, dos de sus sentencias de 2008- y pronunciarse sobre un asunto que años atrás había considerado ajeno a su cometido ${ }^{11}$ (Baraggia, 2017: 275). Y lo hizo justificando su decisión con el argumento de que los preceptos anulados ponían en riesgo el principio constitucional de la igualdad del voto y el carácter necesariamente representativo del proceso electoral. $\mathrm{Y}$ es que los jueces consideraron que el premio a la mayoría desvirtuaba la igualdad de voto entendida a posteriori, es decir, no como el derecho de

10 Commissione per le riforme costituzionali. Per una democrazia migliore. Relazione finale e documentazione. Presieduta da Gaetano Quagliariello. Roma: Presidenza del Consiglio dei Ministri, 2013.

11 En una sentencia de 2010, a propósito de la normativa que regulaba las elecciones europeas, el Tribunal había dejado claro que «este Tribunal no podrá sustituir al legislador en una decisión reservada a este», es decir, en la decisión sobre el régimen electoral aplicable. Con todo, en otra sentencia anterior de 2002, el mismo tribunal había expuesto ya el argumento que le serviría luego para cambiar de criterio: «La determinación de las fórmulas y de los sistemas electorales constituye un ámbito en el que se expresa con el máximo de evidencia la cualidad política de las decisiones legislativas, censurables ante los tribunales de constitucionalidad cuando resulten manifiestamente irracionales» (Fernández Esquer: 2019, 216-217). Quedaba por interpretar, así, cuándo la decisión del legislativo era o no irracional según los jueces. 
todos a participar de la votación, sino como un derecho a que todos los votos contaran lo mismo durante la traducción de preferencias en escańos. No declaró inconstitucional la prima de mayoría en sí misma, que no discutía como opción del legislativo, sino el hecho de que esta se pudiera disfrutar sin haber logrado un porcentaje mínimo. Es decir, el Tribunal consideró que la corrección mayoritaria no era como tal un problema; lo inconstitucional era lo que tachaba de falta de racionalidad en la decisión del legislador, por no haber establecido un umbral mínimo para que una lista pudiera disfrutar de más del $50 \%$ de los escańos. Por otro lado, pero no menos sorprendentemente, el Tribunal consideró que las listas bloqueadas impedían a los electores expresar sus preferencias, por lo que su derecho a la participación en el proceso representativo resultaba dañado (Baraggia, 2017: 276; Faraguna, 2017: 781; Milani y Sorda, 2015: 22-24; Fusaro, 2016: 560-563).

La consecuencia más inmediata de la intervención del Tribunal fue que el régimen electoral quedó automáticamente modificado. La eliminación de los dos puntos inconstitucionales dejó paso a un sistema nuevo sin necesidad de una intervención del legislativo, lo que no dejaba de ser paradójico porque los jueces no devolvieron a la vida el Mattarellum. Al suprimir el premio de mayoría la ley Calderoli, dejó paso a una normativa proporcional solamente corregida por el mantenimiento de las barreras de entrada al recuento. Mientras las Cámaras no fueran capaces de aprobar una nueva ley estaría en vigor un Porcellum mutilado, esto es, lo que se conoció como el Consultellum.

\section{EL FRACASO DE LA REFORMA MÁS AMBICIOSA}

Tiempo después, la iniciativa para una nueva reforma surgió tras los cambios en el liderazgo del centroizquierda. El ascenso de Matteo Renzi dentro del PD le llevó directamente hasta el Gobierno, sucediendo a Letta. Una vez allí tradujo la retórica que le había hecho popular en un plan ambicioso de reformas institucionales. A diferencia de sus predecesores, el equipo de Renzi intentó un cambio global. Quiso combinar una nueva ley electoral con una modificación constitucional de calado que desmontara el sistema de doble cámara soberana, esto es, privando al Senado de participar en la elección y caída de los Gobiernos y potenciando, así, un régimen de gobierno parlamentario a la española. Meses antes había alcanzado un acuerdo político con Berlusconi, conocido como Patto del Nazareno, que comprometía al principal representante del centroderecha en una reforma institucional que incluía un nuevo sistema electoral y que buscaba, de paso, neutralizar la fuerza emergente del M5S (Faraguna, 2017: 783; Fusaro, 2016: 563-565). 
El proyecto de ley electoral presentado por el Gobierno Renzi tuvo una tramitación parlamentaria rápida gracias a la aplicación extraordinaria de la guillotina (Baraggia, 2017: 277). El Senado aprobó el texto definitivo el 27 de enero de 2015, siendo ratificado por la otra Cámara el 4 de mayo. Pero hubo fuertes tensiones con la oposición y Renzi tuvo problemas con el comportamiento díscolo de algunos de sus propios diputados. La nueva Ley 52/2015, conocida como el Italicum $^{12}$, se ocupaba solo de la regulación de las elecciones a la Cámara de los Diputados, pues su vigencia estaba subordinada a la aprobación simultanea de la reforma constitucional de los títulos I y V de la Constitución - referidos al Parlamento y a la organización territorial, respectivamente- ${ }^{13}$. Esto significaba que no regiría en unos comicios nacionales mientras no se aprobara la reforma del régimen parlamentario. Es más, contenía una clausula de salvaguardia en virtud de la cual, si se disolvían anticipadamente las cámaras, la norma aplicable durante el proceso electoral subsiguiente sería el llamado Consultellum.

De este modo, para acabar de complicar la enrevesada historia de las leyes electorales en la Italia reciente, el Italicum estuvo vigente sin llegar a ser nunca aplicada en unas elecciones porque finalmente la reforma a la que estaba condicionada, la presentada por la ministra de Reformas Constitucionales, Elena Boschi, se malogró en las urnas. Al no lograr los dos tercios de los votos parlamentarios necesarios para un cambio constitucional, el legislativo se pronunció a favor de convocar un referéndum sobre la reforma. Si bien este no era obligatorio, finalmente se celebró el 4 de diciembre de 2016, cumpliéndose así la promesa reiterada por Renzi en los meses previos de consultar a la ciudadanía. La consulta arrojó una mayoría, no amplia pero sí clara, de un $59,1 \%$ en contra de la reforma. Consecuentemente, el Italicum murió sin haber llegado a nacer y víctima, una vez más, de las luchas partidistas incluida la traición de FI, que no pidió el «sí» en la consulta popular- y el empeño de Renzi en convertir la votación en un plebiscito sobre su liderazgo. Para acabar de enmarañar la historia del Italicum, unas semanas más tarde, a primeros de 2017, se conoció una nueva sentencia del Tribunal

12 El apodo Italicum servía para recalcar la idea de continuidad con una supuesta vía italiana plasmada en los niveles municipal, provincial y regional durante las dos décadas previas (Olivetti, 2015: 39).

13 «El Senado habría transformado radicalmente su estructura y sus funciones, componiéndose de 74 consejeros regionales más 21 alcaldes, seleccionados con un método que especificar en leyes sucesivas». Además, la propuesta de reforma constitucional también incluía interesantes cambios en los requisitos para la utilización del referéndum abrogatorio y, más importante si cabe, reforzaba la capacidad del Ejecutivo para gobernar por decreto (Vespaziani, 2017: 12-13). 
Constitucional que, como se verá más adelante, volvía a inmiscuirse en el asunto de las leyes electorales y anulaba partes decisivas del nuevo texto (Pasquino y Valbruzzi, 2017: 152-153; Baraggia, 2017: 278; Vespaziani, 2017: 17-19; Bianchi, 2017: 325; Olivetti, 2015: 35-40).

La Ley 52/2015 mantenía, en principio, un sistema proporcional. El número de escańos obtenidos por cada lista se calculaba mediante un reparto proporcional, con una barrera de entrada del 3\% — una barrera baja si se compara con las establecidas en leyes anteriores, si bien ahora calculada a nivel nacional- . Si la lista vencedora sobrepasaba el $40 \%$ del total de votos y lograba 340 o más escaños (sobre un total de 618, sin contar otros 12 escaños de elegidos en una circunscripción exterior), se procedía al reparto sin más y el sistema podía considerarse puramente proporcional. Pero si ninguna lista llegaba a ese porcentaje, la ley fijaba una segunda vuelta donde solo podían competir las dos listas más votadas y sin que fuera posible alterar la composición de las candidaturas iniciales. Tras esa nueva votación, la lista ganadora a nivel nacional se llevaba el premio a la mayoría, obteniendo los 340 escaños $^{14}$.

El Italicum introducía una novedad relevante para el funcionamiento del sistema de partidos en un futuro régimen bicameral asimétrico. Durante la tramitación en el Senado se decidió que el premio a la mayoría (bien habiendo pasado del $40 \%$ en primera vuelta o bien habiendo ganado en segunda) se atribuyera solo a una lista, luego no podía haber unión circunstancial de listas para lograr el premio ni se permitía una alianza ad hoc para afrontar la segunda vuelta (Emanuele, 2015; Olivetti, 2015: 42-51; D’Alimonte, 2015: 287).

Se mantenían las circunscripciones plurinominales, descartándose la vuelta al distrito uninominal mayoritario de 1993, al que se oponía el grupo de Berlusconi. El número quedó establecido en veinte, correspondientes a cada una de las regiones italianas, dentro de las cuales se englobaban varios colegios donde se elegía entre tres y nueve diputados, dependiendo de la población censada ${ }^{15}$. Los ciudadanos tendrían que elegir entre listas no bloqueadas que podían contener entre un $50 \%$ y un $100 \%$ de los diputados elegidos en ese colegio. Así, se podía expresar preferencia por cada uno de los integrantes de la lista, aunque el cabeza de lista sí estaba bloqueado. Por otra parte, mientras que los cabezas de lista, es decir, los líderes nacionales y regionales más conocidos, podían presentarse en diversos colegios (hasta diez)

14 En cuanto a la elección de candidatos, una vez establecidos los escaños de cada lista, resultan elegidos el cabeza de lista y aquellos candidatos que mayor respaldo hayan obtenido. O bien, a igual respaldo, según el orden establecido en la papeleta.

15 Salvo en los casos del Valle d'Aosta y el Trentino Alto Adige, en los que regían características especiales. 
y decidir a posteriori por cual optaban caso de ser elegidos en varios, el resto de los candidatos solo podían aparecer en una lista.

Este sistema mixto o de lista semiabierta fue también el fruto de transacciones mutuas. En este caso, Berlusconi, conocido partidario de las listas cerradas, por lo que estas implican como refuerzo del liderazgo dentro de un partido centralizado, cedió a la presión de Renzi y se encontró el punto de equilibrio en el que los partidos conservarían el control de los cabezas de lista y el lugar por el que decidían salir, mientras que los votantes podrían expresar preferencias sobre el resto de la lista. Esto, traducido en escaños para el partido ganador, significaba: cien candidatos controlados por el partido y doscientos cuarenta dependientes de las preferencias de voto, todo, claro está, dependiendo de la disciplina del votante a uno u otro lado del espacio ideológico (D’Alimonte, 2015: 288).

Se introdujo también, y esto es novedoso respecto de los sistemas electorales vigentes en otros países europeos, una garantía de equilibrio de género. Por debajo del cabeza de lista bloqueado, el resto debían presentarse en un orden de género alternativo, es decir, no podía haber dos candidatos del mismo sexo seguidos. Se aseguraba así que la mitad de la candidatura estuviera formada obligatoriamente por mujeres. Y para evitar que el elector pudiera prescindir de los candidatos de uno de los dos géneros, se limitaba la capacidad de este para elegir solo nombres de un mismo sexo al hacer uso de su voto preferencial, dado que esto último implicaba voto nulo.

En definitiva, el Italicum establecía una vez más un sistema mixto, en el que la naturaleza proporcional experimentaba una corrección mayoritaria gracias a una segunda vuelta que permitía asegurar a la lista más votada una mayoría parlamentaria amplia. Y esto, recuérdese, se hacía pensando en un nuevo régimen parlamentario en el que la confianza del Gobierno dependería solo de la Cámara de los Diputados. De este modo, la lista más votada en segunda vuelta se aseguraba una mayoría no ya parlamentaria, sino de Gobierno. Como explicaba uno de sus principales defensores, se trataba de un régimen "majority-assuring but not 'minority-unfriendly", es decir, que combinaba varias medidas para lograr que las elecciones produjeran un ganador claro, pero a la vez pretendía asegurar la representación de las oposiciones, reservándolas 278 escaños, esto es, un $46 \%$ del total (D'Alimonte, 2015: 287).

El Italicum fue, de este modo, el resultado de un proyecto impulsado por Renzi, pero diseñado en la negociación con FI, a la que aquel necesitaba para la votación del Senado. A priori, Renzi y Berlusconi estaban de acuerdo en dejar atrás cualquier forma de proporcionalidad pura, pero disentían en cuestiones claves; y estaban los puntos en los que el líder de FI se había mostrado siempre inamovible, como su negativa a los distritos uninominales, a la 
segunda vuelta y a las listas abiertas. Esto, como bien ha explicado D'Alimonte, dejaba muy pocas opciones, aunque alguna era viable y había dado resultados positivos para la gobernabilidad en otros casos europeos: el modelo español de proporcionalidad corregida con listas bloqueadas. De hecho, la negociación se produjo inicialmente en torno a una fórmula que trasladase el sistema español. Sin embargo, la oposición que levantó fue insalvable y el compromiso entre la apuesta de Renzi por el mayoritario y la negativa de Berlusconi a los distritos uninominales se resolvió con la prima de mayoría — que, evidentemente, recordaba a la ley Calderoli, si bien corregida para salvar los problemas planteados por el Tribunal Constitucional - y la segunda vuelta —aquí, como es obvio, Berlusconi capituló—. Finalmente, este último también cedió ante la exigencia planteada por Angelino Alfaro, el líder del Nuovo Centro Destra (NCD), un grupo minoritario, pero que Renzi también necesitaba para sacar adelante su proyecto: que hubiera una única barrera a nivel nacional en el $3 \%$ y que la prima se aplicara solo a listas individuales y no a coaliciones. Esto chocaba con el deseo inicial de Berlusconi de forzar un sistema de barreras y de premios que potenciara la formación de coaliciones preelectorales. Finalmente aceptó, en lo que, como explica D'Alimonte, resultó ser "un misterio», habida cuenta de que sus expertos y compañeros de partido le advirtieron sobre las consecuencias negativas de competir con el PD sin la opción de agrupar el voto de centroderecha en una coalición amplia (D'Alimonte, 2015: 289-290; Pasquino, 2015: 297-298).

El Italicum murió sin haber llegado a aplicarse tras el fracaso de Renzi en el referéndum de diciembre de 2016. Fue víctima de quienes criticaban que una norma diseñada para favorecer la formación de mayorías debilitaría el sistema representativo al permitir un Ejecutivo muy fuerte. Ciertamente, los errores de Renzi coadyuvaron a esa interpretación, en la medida en que su forma de afrontar el referéndum favoreció el discurso de los críticos del Italicum. Estos argumentaron que una ley electoral como esa serviría a Renzi para convocar elecciones y, aprovechando el buen momento del PD, consolidar un poder como ningún presidente del Consejo había tenido en Italia desde la época de Mussolini. Al identificar los resultados de la votación con el apoyo o el rechazo a su persona ${ }^{16}$, Renzi contribuyó a colocar los términos del debate fuera de la cuestión que en verdad se debatía: el modelo parlamentario y una ley electoral que incentivara la gobernabilidad sin menoscabar radicalmente la representatividad de la Cámara. Como ha explicado convincentemente Bianchi, la consecuencia más negativa de esos errores fue unir a una oposición dispersa y enfrentada en contra de la reforma del sistema,

16 La Vanguardia, 6-12-2016. 
llegando a perder, incluso, el apoyo de votantes de su propio partido y de algunos aliados circunstanciales. Y es que Berlusconi, si bien había protagonizado el Patto del Nazareno, acabó en el heterogéneo bando que apoyó el «no» en el referéndum, donde estaban el M5S, la Lega y Fratelli d'Italia (Bianchi, 2017: 320-325).

Con todo, el Italicum recibió desde muy temprano críticas que debilitaban su viabilidad a medio y largo plazo. Se objetó contra el ballottaggio por considerar que desvirtuaba la representación y premiaba a un partido que podía haber tenido un resultado mediocre en la primera vuelta; o también se criticó el bloqueo de los cabezas de lista alegando que se depositaba en sus manos un poder excesivo (Fusaro, 2016: 569). El politólogo Gianfranco Pasquino condensó ese espíritu crítico cuando advirtió que el Italicum, combinado con un nuevo sistema de bicameralismo asimétrico, concedería un "poder político sin precedentes" al presidente del Ejecutivo y a su mayoría parlamentaria (Pasquino, 2015: 299). Así, los críticos más académicos negaban que la nueva ley pudiera sentar las bases de un bipartidismo favorable a la estabilidad del Ejecutivo, y creían, por el contrario, que serviría para garantizar un largo periodo de poder al PD de Renzi en un escenario de centroderecha dividido y con un partido antisistema como el M5S creciendo con fuerza.

Además, el Italicum se encontró con objeciones desde el campo jurídico. Rápidamente se cuestionó que se ajustara a lo establecido por el Tribunal Constitucional en 2014. Los partidarios de la ley sostenían que el obstáculo de inconstitucionalidad se había salvado manteniendo en la papeleta el voto preferencial por debajo del cabeza de lista, y que ahora la prima de mayoría sí aparecía vinculada a un porcentaje mínimo de votos. Sin embargo, la duda principal se refería a la existencia de una segunda vuelta a la que solo pasaban dos listas. Finalmente, el 26 de enero de 2017, poco después del terremoto desencadenado por el referéndum y la dimisión de Renzi, el Alto Tribunal italiano terció de nuevo. Aunque el Italicum dejaba de tener sentido tras el no a una reforma constitucional de la que dependía, el Tribunal hizo pública una sentencia que declaraba inconstitucionales dos aspectos: la segunda vuelta y el derecho de los cabezas de lista a decidir a posteriori del escrutinio el lugar por el que resultar electos. Por otro lado, los jueces aceptaban ahora la constitucionalidad del premio a la mayoría y el hecho de que el primero en la lista estuviera bloqueado y no pudiera ser objeto de censura por parte del elector ${ }^{17}$.

El Tribunal insistió en mantenerse dentro del criterio expuesto en 2014, esto es, justificando la interferencia en materia tan política como la electoral por el hecho de que le correspondía velar por la superioridad jurídica del

17 El Pais, 26-1-2017. 
principio constitucional de la representación. En su opinión, esa superioridad había sido nuevamente menoscabada porque la segunda vuelta, tal y como estaba regulada en el Italicum, primaba de forma desproporcionada el valor de la gobernabilidad. Los jueces no declaraban inconstitucional la segunda vuelta en sí misma; sostenían que esta podría ser constitucional siempre que existieran mecanismos que aseguraran que no se alteraba radicalmente la expresión de preferencias en la primera. Y esto no lo veían asegurado en el Italicum porque, para ellos, la segunda vuelta era "una continuación de la primera», pero habiendo mutilado de antemano la oferta sobre la que los ciudadanos podían decidir. Se referían a que, puesto que la ley no permitía la formación de coaliciones ad hoc para la segunda vuelta y solo podían pasar las dos listas más votadas, los ciudadanos se veían obligados a elegir entre dos candidaturas que muchos de ellos podían haber rechazado de antemano. En definitiva, el Tribunal atacaba la segunda vuelta con el mismo o parecido argumento con el que había tumbado el premio a la mayoría de la ley Calderoli, esto es, que el artículo 48 de la Constitución, que establecían la igualdad del derecho al voto, había sido violentado al aplicarse un premio de segunda vuelta sobre un partido cuyo porcentaje de voto en la primera podía haber estado muy por debajo de la mayoría y al que solo se le exigía haber pasado el umbral del $3 \%$ del voto nacional. Consideraba, en definitiva, que la regulación decidida por el legislativo sobre la segunda vuelta era «manifiestamente irrazonable» ${ }^{18}$ (Faraguna, 2017: 784-788; Baraggia, 2017: 278; Vespaziani, 2017: 18-19).

Además, el Tribunal también argumentó la inconstitucionalidad de la libertad de los cabezas de lista para presentarse por varias circunscripciones y decidir a posteriori con cuál de las posibles victorias se quedaban. Para los jueces, nuevamente, esto lesionaba el derecho constitucional al voto de los italianos porque no eran ellos, sino el candidato privilegiado con el primer puesto, el que podía decidir a posteriori el orden de adjudicación de puestos en función de cuál fuera su elección. Así, en opinión del Tribunal, la libre elección tras el recuento por parte del cabeza de lista constituía una acción inadmisible por cuanto distorsionaba la naturaleza del voto de preferencia.

El pronunciamiento del Constitucional volvía a mostrar la enorme dificultad de emprender una reforma electoral con garantías de éxito en un entorno de fragmentación de partidos; peor aún, sin un acuerdo sólido sobre la importancia de favorecer la gobernabilidad en la política italiana. El

18 Como ha señalado Baraggia (2017: 278), no se puede excluir que "the Court's reasoning would have been different if the Italicum had conceived the runoff as a new electoral competition, admitting coalitions of parties instead of restricting it to only two lists». 
horizonte se presentaba todavía más oscuro si se tiene en cuenta la crisis posterior al referéndum y lo que ya nadie negaba, esto es, que el bipolarismo fragmentado, presente desde los primeros compases de la segunda república, había entrado en crisis y nuevos partidos desafiaban no solo a los polos tradicionales, sino a algunos de los pocos consensos de la política italiana, como el compromiso firme con el europeísmo.

\section{UN NUEVO Y CRITICADO RÉGIMEN MIXTO}

A comienzos de 2017, con el paquete de reformas Renzi-Boschi paralizado por el referéndum y el espíritu del Italicum demolido por el Tribunal, la situación no podía ser más enrevesada. Al Gobierno Renzi le había sucedido un Gabinete de continuidad, apoyado en el PD y presidido por el exministro de Exteriores del anterior Ejecutivo, Paolo Gentiloni. Si se celebraban elecciones antes de que se aprobara una nueva reforma electoral, el régimen que aplicar tendría que ser dual. Por un lado, el pronunciamiento judicial había dejado en pie una especie del Italicum mutilado, sin segunda vuelta, para la Cámara de Diputados, esto es, un sistema puramente proporcional en el caso de que ninguna lista consiguiera por sí sola el $40 \%{ }^{19}$. Por otro lado, el Consultellum seguía vigente para las elecciones al Senado. En ese contexto, el grupo emergente, el M5S, el que parecía mejor situado para capitalizar el «no» a Renzi haciendo valer, en otros, su firme oposición al Patto del Nazareno y al Italicum, no tardó en pedir unas elecciones inmediatas. "Hay que ir a votar inmediatamente», declaró Grillo nada más conocerse la sentencia, asegurando que podían llegar por sí solos al $40 \%$ y lograr el premio a la mayoría. Por consiguiente, la división respecto del sistema electoral seguía muy viva. Es más, alcanzaba también al interior de los propios partidos; en el PD ni siquiera había unanimidad sobre lo que algunos consideraban como la salida más rápida y realista: componer una mayoría simple en las Cámaras para volver al Mattarellum, aunque fuera temporalmente ${ }^{20}$.

Como era previsible, la distancia que separaba las posturas entre los distintos grupos disminuyó en la medida en que la proximidad de unas elecciones generales —en principio previstas para el otoño de 2017, aunque finalmente celebradas en marzo de 2018- hizo más urgente aprobar una

19 Aunque algunos autores sostuvieron que, tras la decisión del Tribunal, Italia simplemente quedaba sin normativa para la elección de la Cámara de los Diputados y no se podrían celebrar elecciones por el momento (Pasquino y Valbruzzi, 2017: 159).

20

El País, 26-1-2017. 
normativa electoral. A comienzos de junio de 2017 se conocía la existencia de negociaciones sobre una posible reforma electoral entre los líderes de FI, el PD y el M5S. En ese momento se barajaba un posible acuerdo acerca de un sistema proporcional con una barrera nacional situada en el $5 \%$ y sin premio alguno para la lista más votada. Aunque se contaba con el impacto negativo que esto pudiera tener en los grupos pequeños, parecía claro que, con los grillini subiendo, un escrutinio proporcional devolvería unas Cámaras con tres grandes grupos y de mayorías difíciles, quizás haciendo inevitable una gran coalición a la italiana ${ }^{21}$.

Como explicara D’Alimonte, la situación a comienzos del verano de 2017 no podía ser más endiablada. Renzi, a quien movía el deseo de ir cuanto antes a unas elecciones, no tenía una preferencia bien definida sobre el sistema electoral, si bien parecía dispuesto a algún tipo de arreglo con el modelo alemán en mente. Berlusconi, por el contrario, no tenía prisa con las urnas, pero mantenía su veto a una normativa basada en circunscripciones uninominales y prefería claramente un sistema proporcional puro. En cuanto al presidente de la República, Sergio Mattarella, las elecciones anticipadas no eran una opción, pero sí consideraba imprescindible aprobar un sistema electoral «armonizado» para las dos Cámaras. Por otra parte, una barrera del $5 \%$ significaba en la práctica que probablemente solo cuatro partidos pasarían al recuento: PD, M5S, FI y la Lega (D’Alimonte; 2017a).

Tras el verano se desvaneció la disolución de las Cámaras y se produjo un nuevo acercamiento entre el PD y FI, una especie de renovación del Patto del Nazareno que permitió la aprobación de una nueva ley electoral, sumando además a la Lega. Su tramitación parlamentaria fue bastante agitada, dado que, nuevamente, el M5S quedó fuera del acuerdo y una minoría escindida del PD se opuso. El Gobierno recurrió a una moción de confianza para evitar que la discusión de enmiendas hiciera naufragar el acuerdo, una moción que impedía votar en secreto a los diputados y facilitaba el control ante posibles indisciplinas. Por su parte, los grillini protagonizaron una protesta teatral a las puertas de la Cámara de los Diputados para denunciar lo que interpretaban como una confabulación para impedirles llegar al Gobierno. En cuanto a Berlusconi, parecía decidido a apoyar una reforma basada en la proporcionalidad, consciente de la debilidad del centroderecha y temeroso de que una fórmula mixta con premio a la lista más votada pudiera beneficiar a un M5S al que las encuestas colocaban como primera opción de los italianos ${ }^{22}$.

21 La Vanguardia, 1-6-2017 (D'Alimonte, 2017b).

22 La Vanguardia, 12-10-2017 y El País, 12 y 14-10-2017. También P. Martín de Santa Olalla, «Renzi, Berlusconi y la vuelta al Pacto del Nazareno», El Pais, 19-10-2017. 
Finalmente, la nueva ley fue aprobada en el Senado el 26 de octubre con 214 votos a favor, 61 en contra y 2 abstenciones. Como sus antecesoras, enseguida fue conocida con un apodo, el Rosatellum bis o, simplemente, el Rosatellum, que hacía referencia al nombre del impulsor en la Cámara del proyecto presentado antes del verano, el diputado del PD Ettore Rosato. Establecía de nuevo un sistema electoral mixto, fruto, como sus predecesoras, de un tira y afloja entre diversos intereses y cálculos. Se aplicaría por igual a las dos Cámaras, es decir, respondía a la pretensión del presidente Mattarella de un sistema "armonizado». Su naturaleza mixta radicaba en que se combinaban dos niveles, uno proporcional y otro mayoritario. Pero, a diferencia del modelo alemán, ambos no estaban conectados formalmente, sino que eran independientes. Por el sistema mayoritario se elegía el 36\% de los escaños de ambas Cámaras, delimitándose 232 y 109 distritos uninominales donde, siguiendo la lógica del modelo inglés, el ganador se llevaba el puesto. A la vez, el $64 \%$ de los escańos restantes (386 diputados y 200 senadores) se elegirían por escrutinio proporcional ${ }^{23}$. En este caso, el votante debía optar entre diferentes listas bloqueadas, formadas por unos pocos candidatos dentro de la circunscripción plurinominal. No podía, por tanto, establecer preferencias, lo que si bien podía suponer un problema con la doctrina establecida por el Tribunal, parecía quedar salvado por el hecho de que una tercera parte de los integrantes de las futuras Cámaras sí fuera fruto de la elección personal del votante. El elector debía apoyar al mismo partido tanto en el cupo mayoritario como en el proporcional, o bien respaldar un nombre del mayoritario, dejando en blanco la parte correspondiente a las listas; no podía elegir, por tanto, a un candidato del mayoritario adscrito a un partido y luego seleccionar la lista de otro grupo diferente. En cuanto a las barreras, cuestión que había sido bastante discutida en los meses previos, finalmente no se estableció en el $5 \%$ que defendían quienes, en la misma línea del Italicum, estaban a favor de reducir la fragmentación y favorecer la gobernabilidad. La cifra para que una lista pudiera entrar en el reparto proporcional se quedó en el $3 \%$. No obstante, como la nueva normativa permitía la formación de coaliciones, se estableció también una barrera más alta, del $10 \%$, para cuando se tratara de una lista conjunta ${ }^{24}$.

El Rosatellum era la quinta ley electoral desde que se inauguró la segunda república y, a juzgar por las críticas que recibió en la última fase de la tramitación, no parecía destinada a ser la última. En el ambiente pesaba la idea de que

23 Además, en una circunscripción exterior y por sistema de listas se repartían doce y seis escańos más por la Cámara de Diputados y el Senado, respectivamente.

24

La Vanguardia, 27-10-2017 y El País, 28-10-2017 (D'Alimonte, 2017c, 2017d; Fernández Esquer, 2019: 225-226). 
se trataba de un acuerdo circunstancial entre el PD y FI. Ambos, amenazados por el ascenso de un tercero, habían escogido una fórmula que incentivara las coaliciones en sus respectivos campos, y a sabiendas de que el M5S se presentaría en solitario. Así las cosas, cuando poco después se convocaron elecciones para marzo de 2018, algunos estaban convencidos de que el nuevo régimen electoral promovía la inestabilidad. Los críticos por la izquierda de Renzi calificaron la ley Rosato de "chapuza» que no devolvería un ganador claro y convertiría nuevamente la formación de Gobierno en un asunto de negociaciones postelectorales ${ }^{25}$. Significativamente, cuando el 4 de marzo de 2018 los italianos acudieron a votar, aparte de la incertidumbre natural sobre los resultados y de cierta confusión en algunos colegios por lo complicado del nuevo sistema - que hizo necesario elaborar un documento con instrucciones a disponibilidad de los electores en cada mesa-, no eran pocos los comentarios en los medios que señalaban como una de las tareas de las futuras Cámaras la aprobación de una nueva ley electoral ${ }^{26}$.

\section{REFORMA ELECTORAL Y GOBERNABILIDAD. EL FRACASO DEL ITALICUM}

La política de reformas electorales en la Italia de la segunda república resulta, cuanto menos, sorprendentemente cambiante, al menos a partir de 2005. No es extraño que haya constituido un desafío para los especialistas. No en vano, la literatura había tendido a considerar que el patrón de las democracias occidentales durante la segunda mitad del siglo xx confirmaba una muy baja tendencia al cambio, al menos en lo referido a las «major electoral reforms» y hasta que se produjeron los cambios en Italia, Japón y Nueva Zelanda en la década de 1990 (Katz, 2005: 57-58; Núñez y Kristof, 2016: 454-455). No obstante, otras cuestiones resultan también relevantes, como la relación entre el sistema electoral y el sistema de partidos, o el impacto de las reglas electorales sobre la eficacia y representatividad del sistema parlamentario.

A la pregunta de cuánto cuenta un sistema electoral se han dado respuestas diferentes. De un lado quienes sostienen, con Sartori como principal representante, que se pueden formular generalizaciones relevantes sobre el impacto del sistema electoral, dándose una influencia combinada entre este y el sistema de partidos — dependiendo, en este último caso, de su fortaleza o debilidad

25 El entrecomillado, en una entrevista a Massimo D`Alema. El País, 29-1-2018. Napolitano, en La Vanguardia, 27-10-2017.

26 «Nos gusta hacerlo todo complicado», La Vanguardia, 5-3-2018. 
estructural- . Por consiguiente, se reconocen y analizan las oportunidades de hacer ingeniería con las reglas electorales, esto es, utilizarlas para incentivar o desincentivar aspectos como la variabilidad de la oferta partidista o el grado de eficacia del sistema para propiciar la formación de Gobiernos estables. De otro, aquellos que no consideran que la normativa electoral sea una variable claramente independiente y sostienen, como es el caso de Rokkan, que la interacción entre los partidos y la gestión de la competencia y el disenso resultan decisivas para la formación y variación de un sistema electoral, que siempre responde a un contexto histórico e ideológico concreto. O quienes concluyen, como Lijphart, que si bien el sistema electoral impacta sobre el grado de proporcionalidad, no condiciona de la misma manera al sistema de partidos, dada la presencia relevante de factores como «los cálculos estratégicos de las élites y los votantes». Hay, además, posiciones intermedias, como cuando Rae señaló la importancia de los «efectos próximos» del sistema electoral, especialmente en cuanto a la limitación del grado de proporcionalidad, pero advirtiendo también sobre el influjo de los sistemas de partidos en la configuración de los regímenes electorales (Nohlen, 2013:16-20, 28-29; Sartori, 1994: 39-65; Duverger, 1970: 166-178; Lijphart, 1995; Rae, 1967; Colomer, 2003).

La experiencia italiana reciente muestra hasta qué punto las expectativas iniciales ligadas a un cambio de las reglas electorales pueden frustrarse como resultado del contexto partidista y de la pervivencia de prácticas divisorias y letales para la institucionalización de los partidos, tales como la debilidad de las lealtades de los cargos electos, la indisciplina o la fragmentación crónica.

La ley que en 1993 inauguró un nuevo tiempo electoral para la segunda república tuvo efectos no previstos. Es verdad que propició una suerte de competición bipolar entre coaliciones, y que mejoró la conexión entre el acto de votar y el control sobre la formación de Gobierno, en tanto que los electores conocían de antemano quien encabezaba su coalición preferida y podían presuponer que la victoria se traduciría en el control del Ejecutivo. Pero otras expectativas se frustraron parcialmente dado que el sistema de partidos tradicional se derrumbó y la nueva normativa se aplicó en un contexto de incipiente institucionalización de los partidos emergentes. Puesto que el enfrentamiento se planteó entre coaliciones, el peso de los grupos minoritarios se sobredimensionó, convirtiéndose estos en portadores de una herramienta poderosa de chantaje que incentivaba el faccionalismo y menoscababa la estabilidad de los Gobiernos. Por otra parte, como el bipolarismo no se estableció entre organizaciones disciplinadas y cohesionadas, sino entre coaliciones heterogéneas con vocación de catch-all, si bien los Ejecutivos podían formarse rápidamente como resultado de las votaciones, a medio plazo resultaban inestables. Así, los datos de rotación de los Gobiernos entre 1994 y 2005 resultaron peores que los de la denostada época anterior. Y la concentración de voto entre los dos 
principales partidos del sistema, si bien creció entre 1994 y 2001, se mantuvo entre 15 y 20 puntos por debajo de los porcentajes logrados entre 1948 y 1987 (Pasquino y Valbruzzi, 2015: 438-439, 442; Regalia, 2018: 86). Esto puso de manifiesto que la gobernabilidad no era solo variable de la normativa electoral, es decir, que no bastaba con demoler el método proporcional si el nuevo sistema mixto con corrección mayoritaria tenía que vérselas con un mapa de partidos incierto y más fragmentado que años atrás. Como señalara Bardi (2007: 729), si bien el Mattarellum incentivaba un "grado de competición centrípeta más moderada que en el pasado", al mismo tiempo la lógica de la formación de Gobierno y el mantenimiento de las mayorías parlamentarias que lo habían gestado estimulaba un "comportamiento centrífugo y altamente polarizado similar al de la era anterior a 1992».

La modificación de la ley electoral en 2005 inauguró un nuevo período. Aunque la oposición que despertó auguraba que sería breve, resultó finalmente más longeva y estuvo vigente durante buena parte del período que comprende este dossier (2008-2018). No contó con los mismos consensos de partida que su predecesora ni vino precedida de una movilización popular que actuara como desencadenante. En todo caso, su diseño pareció encajar bien en el supuesto de que los sistemas electorales tienen consecuencias importantes sobre el sistema de partidos, en tanto que sus impulsores buscaban, básicamente, incentivar la unidad en la coalición de centroderecha y debilitar a un centroizquierda pujante.

Como se explicó más arriba, las críticas de Porcellum fueron enérgicas e insistentes, básicamente por partidistas, pero también apelando a una idea que ha tenido bastante eco en la Italia de estos últimos ańos, hasta el punto de estar también detrás de la campańa en contra de la posterior reforma RenziBoschi. Es la que descalifica, por contraria a la tradición republicana de postguerra, toda normativa electoral que promueva alguna forma de premio o de ballottaggio para potenciar la formación de mayorías parlamentarias sólidas tras el cierre de las urnas. Peor todavía si, además de primar la gobernabilidad sobre la representación, esa norma incluye instrumentos que favorezcan la centralización de los partidos mediante el control de listas cerradas o semibloqueadas. Todo esto significa que, visto con la perspectiva temporal suficiente y teniendo en cuenta tanto los pronunciamientos del Tribunal Constitucional en 2014 y 2017, como lo que ocurrió con el Italicum, el problema de la ley Calderoli no fue solo la estrecha visión partidista que la impulsó porque, como señalara Pasquino (2007: 89), siendo esto último cierto, no lo es menos que «muchas» de las críticas del centroizquierda «estuvieron igualmente inspiradas por el partidismo». Y este contribuyó a difuminar un problema más grave que afectaría a todo intento de reforma electoral posterior, esto es, la enorme dificultad de acordar reglas del juego en un contexto de alta volatilidad (Regalia, 2018: 90) e incertidumbre sobre la estabilización del sistema de partidos. 
Peor aún, un sistema de partidos que experimentaba las tensiones centrífugas que se derivaban de una costumbre política persistente: el trasformismo. Esto se traducía en una alta volatilidad postelectoral que debilitaba profundamente la cohesión de las mayorías de Gobierno y socavaba la disciplina interna y, por tanto, la institucionalización de los partidos más importantes y con posibilidades de presidir los Ejecutivos. En este último sentido, la comparativa con la Primera República resulta llamativa. La media de diputados de la Cámara Baja que cambiaron de adscripción durante la legislatura pasó de veintiuno en la década de 1983 a 1994 a ochenta en los años de 1994 a 2006 y, significativamente, siguió creciendo hasta ciento dieciséis en el período que aquí nos interesa, de 2006 a 2017. No es extraño, así, que se haya afirmado que ante estos datos «impresionantes» sobre el transfuguismo posterior a la constitución de las mayorías de Gobierno, «ningún sistema electoral (y menos uno proporcional), puede fortalecer el papel del Ejecutivo sobre un legislativo indisciplinado»(Regalia, 2018: 92-93; Valbruzzi, 2015). A lo que cabe añadir, no obstante, que el diseño de normativas electorales como Porcellum, esto es, con mecanismos que garantizan el protagonismo de los grupos minoritarios, ha jugado claramente en contra del reforzamiento de las maquinarias de partido y, por tanto, incentivado ese transfuguismo. Sin olvidar, además, que las decisiones del Tribunal no han favorecido un cambio significativo de esa tendencia, sino al contrario, en la medida en que los jueces han considerado que el principio de representación es incompatible con mecanismos como las listas cerradas o, peor aún, con la preponderancia de los líderes en esas listas.

Un partidismo proyectado con miras estrechas y una injerencia judicial excesiva podían haber sido parcialmente neutralizados cuando se tramitó la ambiciosa propuesta del Gobierno Renzi para encajar una reforma electoral duradera en un cambio del modelo parlamentario. Es evidente que, más allá de discusiones relevantes sobre los aciertos o errores de Renzi, el propósito de la reforma emprendida por el PD respondía a una interpretación razonada de los problemas que se arrastraban durante varios lustros. Pese a las posiciones argumentadas de los críticos más destacados (Pasquino y Valbruzzi, 2015: 449-451) y descontando que la estrategia del populismo grillino - que había irrumpido con fuerza en las elecciones de 2013 (Bordignon y Ceccarini, 2013; Tarchi, 2015) - no pasaba por contribuir responsablemente a una nueva ley electoral consensuada, el Italicum contenía una propuesta interesante para incentivar a medio plazo un parlamentarismo racionalizado a la italiana y fortalecer la institucionalización de los principales partidos.

La ley de 2015 estaba diseñada para un nuevo régimen parlamentario asimétrico, lo que no debiera olvidarse al hacer un balance. Intentó, además, ser una ley negociada en un amplio espacio ideológico, aunque el acuerdo se 
truncó al final. Obviamente, no se sustrajo al partidismo, como de hecho no puede hacerse en ninguna discusión sobre reformas electorales, dado que los diseñadores de las reglas son los futuros jugadores. $\mathrm{Y}$ hubo expectativas cruzadas, e incluso, como ha explicado D'Alimonte, vetos que desfiguraron el plan inicial. Pero el intento de hacer una norma que incentivara la racionalización de la oferta y contribuyera, en un nuevo molde parlamentario, a una formación más rápida y previsiblemente duradera del Ejecutivo eran sus puntos fuertes. No obstante, su fortaleza era también su debilidad, pues abría la puerta a una posible presidencialización de la política italiana, debilitando la figura del presidente de la República a costa del presidente del Consejo e incentivando unas mayorías parlamentarias más dóciles y disciplinadas. Esto, en un país con una tradición política que asimilaba la formación de mayorías estables con el peligro de fascistización, hizo del Italicum el blanco de críticas cruzadas en las que, en muchos casos, se podía advertir un oportunismo táctico tan llamativo como el que había merecido la ley Calderoli. Así, una "cultura proporcional profundamente arraigada", bien presente también en los razonamientos judiciales ${ }^{27}$, fue la principal barrera contra una norma que pretendía convertir al votante en el protagonista de la elección del presidente del Consejo, especialmente si se pasaba a una segunda vuelta.

Como explicara D'Alimonte, el Italicum, como cualquier otra ley electoral, no podía producir por sí sola una mayor estabilidad de gobierno, pero sí podía estimularla; y un Gobierno más estable sería, a la postre, un Gobierno más responsable. (D’Alimonte, 2016a, 2016b). Desde ese punto de vista, las críticas que recibió la existencia de una segunda vuelta resultaban no ya oportunistas sino desenfocadas. Buscaban desprestigiarla porque desvirtuaba el principio de representación al no permitir que la oferta se limitara en el paso de la primera a la segunda vuelta. Pero, en verdad, una segunda vuelta sin posibilidad de coaliciones ad hoc introducía una corrección mayoritaria que favorecía la futura gobernabilidad e incentivaba el fortalecimiento de dos partidos destacados, obligando así a PD y FI a prepararse para una dura competición con un populismo en auge. Pese a las críticas oportunistas que vinculaban la segunda vuelta con una manipulación para sustraer al votante de expresar preferencias verdaderas, este recurso contaba con una larga trayectoria de defensores entre los académicos italianos, empezando por Sartori. Y uno de los motivos, nada desdeñable, era que la segunda vuelta facilitaba la identificación entre voto y formación de mayorías de Gobierno; pero también

27 «In realtà si dovrebbe dire che non ci siamo mai spostati da una concezione kelseniana della democrazia per cui l'unica forma legittima di governo parlamentare è quella proporzionale» (D’Alimonte, 2016a). 
podía ser un instrumento que coadyuvara a agrupar el voto moderado en un contexto, el de 2013 en adelante, en el que se advertían serías amenazas de polarización en torno a extremos de tinte populista, como confirmarían luego las elecciones de marzo de 2018. Debidamente combinada con la reforma del sistema parlamentario, no era descabellado suponer que el Italicum facilitara una combinación de gobernabilidad, representación equilibrada y diputados más disciplinados.

\section{CONSIDERACIÓN FINAL}

Con motivo de la recurrente discusión que ha culminado en el Rosatellum, el politólogo Angelo Panebianco ha señalado el error de situar el debate sobre las leyes electorales prescindiendo de la experiencia previa y suponiendo que operarán en el vacío, es decir, sin otros mecanismos institucionales o tradiciones políticas que las condicionan y/o pervierten. Así, ha afirmado que todo aquel que asegure que un sistema electoral es capaz de dar estabilidad a la democracia por sí solo "no sabe de qué está hablando» porque eso depende también de otros factores. No obstante, el propio Panebianco ha situado bien el contexto paralizante que ha presidido todo intento de reforma electoral en la Italia de la última década. El diseńo constitucional italiano propicia un régimen de asamblea que prioriza el papel del Parlamento a costa de la estabilidad. En ese sentido, los esfuerzos para construir «un'autentica democrazia gobernante» habrían fracasado. En definitiva, lo que él llama "conservatorismo costituzionale» se habría consagrado en el referéndum que cerró la puerta a la reforma de 2015 y con ella al sistema electoral previsto en el Italicum para una única Cámara gobernante ${ }^{28}$.

La ley Rosato no supuso un cambio sustantivo en cuanto a la relación entre el sistema electoral y la estabilidad de los Gobiernos. El hecho de que fueran los regímenes electorales español o alemán los que estuvieran flotando en el ambiente de las discusiones durante el año 2017, muestra hasta qué punto existía también una opinión proclive al camino de la racionalización del parlamentarismo italiano (D’Alimonte, 2019). No obstante, el periodo 2008-2018 concluyó con nuevas señales — no ya la consolidación de un escenario a tres en el sistema de partidos, sino un nuevo motivo de inquietud con el auge de la Lega de Matteo Salvini como principal impulsor de los resultados del bloque de centroderecha y el debilitamiento, también a la izquierda, del voto no populista (Del Palacio, 2018: 225; Bull y Pasquino, 2018)— que

28 «La solita memoria corta», Corriere della Sera, 21-9-2019. 
invitaban a pensar que los obstáculos para una reforma electoral consensuada y con vocación de permanencia estaban más vivos que nunca. El Rosatellum contó con un apoyo amplio, pero nació en un contexto de incertidumbre que le auguraba poca vida. Buena prueba es esa recurrente aparición de promesas de reforma electoral cada vez que se ha formado un nuevo Ejecutivo desde las elecciones de marzo de 2018. Con todo, esta última ley no supone un cambio sustantivo en esa tendencia a diseñar sistemas mixtos que responden tanto al deseo de complacer demandas cruzadas difícilmente compatibles, como al hecho de que la combinación entre un fundamento proporcional y un correctivo mayoritario no resolverá el problema de la estabilidad en el Gobierno, pero al menos permitirá mantener ese típico equilibrio de la segunda república. Un equilibrio en el que los sistemas electorales están llamados a tener efectos débiles y son otros factores, especialmente la inmadurez y volatilidad tanto del sistema de partidos como de los grupos parlamentarios, los que resultan decisivos.

En definitiva, en la Italia de la década comprendida entre 2008 y 2018 se ha dado una combinación potencialmente explosiva entre la imposibilidad de estabilizar una normativa electoral que, aun siendo mixta, incentivara a los partidos a decidir sus estrategias superando un exceso de cortoplacismo, y un sistema de partidos inestable y fragmentado. Este, además, estuvo fuertemente condicionado por el peso de los grupos pequeños en el diseño de las coaliciones ganadoras y, en tiempos más recientes, se ha visto gravemente erosionado por la aparición de grupos y liderazgos que han hecho de la retorica populista un recurso estrella en una competición donde ya no priman claramente las líneas de división ideológica clásicas.

Al final, en la gestación de todas las reformas electorales habidas en Italia en el periodo que nos ocupa se observa una misma convicción por parte de sus impulsores, esto es, la de que manipulando las reglas del juego podrían alterar el equilibrio de fuerzas pre y postelectoral, así como influir en la formación y estabilidad de Gobiernos. Sin embargo, ha sido la evolución del sistema de partidos y otros factores ambientales los que han condicionado el impacto real de las reformas electorales, distorsionando buena parte de las expectativas iniciales y coadyuvando a crear un clima a favor de su modificación, es decir, favoreciendo la cronificación de la provisionalidad y, al final, debilitando la legitimidad del sistema político en favor del discurso populista.

\section{BIBLIOGRAFÍA}

Baldini, G. (2011). The Different Trajectories of Italian Electoral Reforms. West European Politics, 34 (3), 644-663. Disponible en: https://doi.org/10.1080/01402382.2011.555988. 
Bardi, L. (2007). Electoral change and its impact on the party system in Italy. West European Politics, 30 (4), 711-732. Disponible en: https://doi.org/10.1080/01402380701500256.

Baraggia, A. (2017). Italian Electoral law: A Story of an Impossible Transition? Election Law Journal, 16 (2), 272-279. Disponible en: https://doi.org/10.1089/elj.2016.0405.

Bianchi, D. G. (2017). "I missed a penalty»: the constitutional referendum and Matteo Renzi`s mistakes. Modern Italy, 22 (3), 1-15. Disponible en: https://doi.org/10.1017/ mit.2017.35.

Bordignon, F. y Ceccarini, L. (2013). Five Stars and a Cricket. Beppe Grillo Shakes Italian Politics. South European Society and Politics, 18 (4), 427-449. Disponible en: https://doi. org/10.1080/13608746.2013.775720.

Bull, M. J. y Pasquino, G. (2018). Italian Politics in an Era of Recession: The End of Bipolarism? South European Society and Politics, 23 (1), 1-12. Disponible en: https://doi.org/1 $0.1080 / 13608746.2018 .1436493$.

Chiaramonte, A. (2015). The Unfinished Story of Electoral Reforms in Italy. Contemporary Italian Politics. 7 (1), 10-26. Disponible en: https://doi.org/10.1080/23248823.2014.1 002244 .

Crainz, G. (2015). Italy's political system since 1989. Journal of Modern Italian Studies, 20 (2), 176-188. Disponible en: https://doi.org/10.1080/1354571X.2015.997490.

Colomer, J. M. (2003). Son los partidos los que eligen los sistemas electorales (o las leyes de Duverger cabeza abajo). Revista Española de Ciencia Política, 9, 39-63.

D`Alimonte, R. (2005). Italy: A case of Fragmented Bipolarism. En M. Gallagher y P. Mitchell (eds.). The Politics of Electoral Systems (pp. 253-276). Oxford: Oxford University Press. Disponible en: https://doi.org/10.1093/0199257566.003.0012.

(2013). The Italian elections of February 2013: The end of the Second Republic? Contemporary Italian Politics, 5 (2), 113-129. Disponible en: https://doi.org/10.1080/2 3248823.2013.807599.

- (2015). The new Italian Electoral System: Majority-assuring but minority-friendly. Contemporary Italian Politics, 7 (3), 286-292. Disponible en: https://doi.org/10.1080/2 3248823.2015.1093280.

- (2016a). Governo e Parlamento, quanto pesa l'incognita della legge elettorale. Centro Italiano Studi Electtorali, 27-11-2016. Disponible en: https://bit.ly/3hGL2Mz.

- (2016b). I due turni dell'Italicum: perche Sì. Centro Italiano Studi Elettorali. 15-9-2016. Disponible en: https://bit.ly/3ddg7np.

(2017a). Legge elettorale, le convenienze (e i danni) del «tedesco». Centro Italiano Studi Elettorali, 29-5-2017. Disponible en: https://bit.ly/37G0ELv.

- (2017b). Il patto proporzionale salvato a scapito della governabilità. Centro Italiano Studi Elettorali, 6-6-2017. Disponible en: https://bit.ly/30TCj3F.

- (2017c). Doppio turno contro l'incertezza. Centro Italiano Studi Elettorali, 24-9-2017. Disponible en: https://bit.ly/3edGeMd.

(2017d). Il pallottoliere del Rosatellum. Centro Italiano Studi Elettorali, 15-10-2017. Disponible en: https://bit.ly/2zLuUYY.

- (2019). Una buona notizia: almeno per ora la riforma elettorale non si farà. Centro Italiano Studi Elettorali, 30-9-2019. Disponible en: https://bit.ly/3fxNPpi. 
Del Palacio Martín, J. (2018). Italia, de la antipolítica al populismo. Revista de Estudios Políticos, 181, 219-230. Disponible en: https://doi.org/10.18042/cepc/rep.181.08.

Donovan, M. (1996). Electoral Reform in Italy. Representation, 33 (4), 141-147. Disponible en: https://doi.org/10.1080/00344899608522974.

Duverger, M. (1970). Instituciones politicas y derecho constitucional. Barcelona: Ariel.

Emanuele, V. (2015). L'Italicum punto per punto: ecco cosa prevede. Centro Italiano Studi Elettorali, 18-4-2015. Disponible en: https://bit.ly/3eg436f.

Faraguna, P. (2017). «Do You Ever Have One of Those Days When Everything Seems Unconstitutional?»: The Italian Constitutional Court Strikes Down the Electoral Law Once Again. European Constitutional Law Review, 13, 778-792. Disponible en: https://doi. org/10.1017/S1574019617000372.

Fernández Esquer, C. (2019). El creciente activismo de la Corte Constitucional italiana ante las reformas del sistema electoral nacional. Anuario Iberoamericano de Justicia Constitucional, 23 (1), 209-230. Disponible en: https://doi.org/10.18042/cepc/aijc.23.07.

Fusaro, C. (2016). La nueva ley electoral italiana de 2015, un reto para el parlamentarismo débil. Teoría y Realidad Constitucional, 38, 547-574. Disponible en: https://doi. org/10.5944/trc.38.2016.18594.

Groppi, T. (2008). Formas de gobierno y sistemas electorales en Italia. Revista Española de Derecho Constitucional, 83, 153-173.

Katz, Richard (2005). Why are there so Many (or so Few) Electoral Reforms? En M. Gallagher y P. Mitchell (eds.). The Politics of Electoral Systems. Oxford: Oxford University Press. Disponible en: https://doi.org/10.1093/0199257566.003.0003.

Lijphart, A. (1995). Sistemas electorales y sistemas de partidos: un estudio de veintisiete democracias, 1945-1990. Madrid: Centro de Estudios Políticos.

Massetti, E. (2006). Electoral Reform in Italy: From PR to Mixed System and (almost) Back Again. Representation, 42 (3), 261-269. Disponible en: https://doi. org/10.1080/00344890600844848.

Milani, G. y Sorda, E. (2015). Ley electoral y relevancia. La Corte Constitucional italiana supera una zona de sombra. Justicia Electoral, 15 (1), 17-63.

Nohlen, D. (2004). Sistemas electorales y partidos politicos. Madrid: Fondo de Cultura Económica.

- (2013). Controversias sobre sistemas electorales y sus efectos. Revista Española de Ciencia Politica,31,9-39.Disponible en:https://doi.org/10.22201/iij.24487910e.2013.3.10007.

Norris, P. (1997). Choosing Electoral Systems: Proportional, Majoritarian and Mixed Systems. International Political Science Review, 18 (3), 297-312. Disponible en: https://doi. org/10.1177/019251297018003005.

Núñez, L. y Kristof, J. (2016). Catalysts and barriers. Explaining electoral reform in Western Europe. European Journal of Political Research, 55 (3), 454-473. Disponible en: https:// doi.org/10.1111/1475-6765.12138.

Olivetti, M. (2015). La reforma electoral italiana de 2015. Cuadernos de Pensamiento Político, 47, 35-52.

Pappalardo, A. (1995). La nueva ley electoral italiana. Revista de Estudios Politicos, 89, 61-80. Pasquino, G. (1994). Italia: un sistema político que cambia. Psicología Política, 8, 29-44. 
- (2007). Tricks and Treats: The 2005 Italian Electoral Law and Its Consequences. South European Society and Politics, 12 (1), 79-93. Disponible en: https://doi. org/10.1080/13608740601155500.

- (2015). Italy has yet another electoral law. Contemporary Italian Politics, 7 (3), 293-300. Disponible en: https://doi.org/10.1080/23248823.2015.1070513.

- y Valbruzzi, M. (2015). The impact of the 2013 general election on the Italian political system: The end of bipolarism? Journal of Modern Italian Studies, 20 (4), 438-453. Disponible en: https://doi.org/10.1080/1354571X.2015.1066111.

- y Valbruzzi, M. (2017). Italy says no: the 2016 constitutional referendum and its consequences. Journal of Modern Italian Studies, 22 (2), 145-162. Disponible en: https://doi. org/10.1080/1354571X.2017.1286096.

Rae, D. W. (1967). The Political Consequences of electoral Laws. New Haven: Yale University Press.

Regalia, M. (2018). Electoral Reform as an Engine of Party System Change in Italy. South European Society and Politics, 23 (1), 81-96. Disponible en: https://doi.org/10.1080/13 608746.2018.1432245.

Renwick, A., Hanretty, Ch. y Hine, D. (2009). Partisan self-interest and electoral reform: The new Italian electoral law of 2005. Electoral Studies, 28 (3), 437-447. Disponible en: https://doi.org/10.1016/j.electstud.2009.04.003.

Renwick, A. (2010). The Politics of Electoral Reform. Changing the Rules of Democracy. Cambridge: Cambridge University Press. Disponible en: https://doi.org/10.1017/ CBO9780511676390.

Sartori, G. (1994). Ingeniería constitucional comparada. Una investigación de estructuras, incentivos y resultados. México DF: Fondo de Cultura Económica.

Tarchi, M. (2015). Italy: The promised land of populism? Contemporary Italian Politics, 7 (3), 273-285. Disponible en: https://doi.org/10.1080/23248823.2015.1094224.

Valbruzzi, M. (2015). Transformismo. En E. Jones y G. Pasquino (eds.). Oxford Handbook of Italian Politics (pp. 26-40). Oxford: Oxford University Press. Disponible en: https://doi. org/10.1093/oxfordhb/9780199669745.013.3.

Vespaziani, A. (2017). El referéndum constitucional y la saga de las reformas institucionales en Italia: Much ado about nothing. Revista de Derecho Constiucional Europeo, 27, 5. Disponible en: https://doi.org/10.4013/rechtd.2017.92.01. 